\title{
A Cross-country Comparison of Success Factor Priorities for Health Information Technology Managers Evidence of Convergence in the Nordic Countries
}

Nguyen, Thi Thanh Hai; Eikebrokk, Tom Roar; Moe, Carl Erik; Medaglia, Rony; Larsson, Hannu; Tapanainen, Tommi

Document Version

Accepted author manuscript

Published in:

Proceedings of the 48th Annual Hawaii International Conference on System Sciences, HICSS-48

DOI:

10.1109/HICSS.2015.342

Publication date:

2015

License

Unspecified

Citation for published version (APA):

Nguyen, T. T. H., Eikebrokk, T. R., Moe, C. E., Medaglia, R., Larsson, H., \& Tapanainen, T. (2015). A Crosscountry Comparison of Success Factor Priorities for Health Information Technology Managers: Evidence of Convergence in the Nordic Countries. In T. X. Bui, \& R. H. Sprague Jr. (Eds.), Proceedings of the 48th Annual Hawaii International Conference on System Sciences, HICSS-48 (pp. 2824-2833). [7070157] IEEE. Proceedings of the Annual Hawaii International Conference on System Sciences https://doi.org/10.1109/HICSS.2015.342 Link to publication in CBS Research Portal

\section{General rights}

Copyright and moral rights for the publications made accessible in the public portal are retained by the authors and/or other copyright owners and it is a condition of accessing publications that users recognise and abide by the legal requirements associated with these rights.

Take down policy

If you believe that this document breaches copyright please contact us (research.lib@cbs.dk) providing details, and we will remove access to the work immediately and investigate your claim. 


\title{
A Cross-country Comparison of Success Factor Priorities for Health Information Technology Managers: Evidence of Convergence in the Nordic Countries
}

\section{Thi Thanh Hai Nguyen, Tom Roar Eikebrokk, Carl Erik Moe, Rony Medaglia, Hannu Larsson, and Tommi Tapanainen}

Article in proceedings (Post print version)

\begin{abstract}
CITE: A Cross-country Comparison of Success Factor Priorities for Health Information Technology Managers : Evidence of Convergence in the Nordic Countries. / Nguyen, Thi Thanh Hai; Eikebrokk, Tom Roar; Moe, Carl Erik; Medaglia, Rony; Larsson, Hannu; Tapanainen, Tommi. Proceedings of the 48th Annual Hawaii International Conference on System Sciences, HICSS-48. ed. / Tung X. Bui; Ralph H. Sprague Jr.Los Alamitos, CA : IEEE, 2015. p. 2824-2833 (Annual Hawaii International Conference on System Sciences. Proceedings, Vol. 48).
\end{abstract}

001: 10.1109/HICSS.2015.342

Uploaded to Research@CBS: November २०16

(C) २०16 IEEE. Personal use of this material is permitted. Permission from IEEE must

be obtained for all other uses, in any current or future media, including reprinting/republishing this material for advertising or promotional purposes, creating new collective works, for resale or redistribution to servers or lists, or reuse of any copyrighted component of this work in other works. 


\section{A Cross-country Comparison of Success Factor Priorities for Health Information Technology Managers: Evidence of Convergence in the Nordic Countries}

\author{
Thi Thanh Hai \\ Nguyen \\ University of \\ Eastern Finland, \\ Finland \\ haintt@akane.wa \\ seda.jp
}

\author{
Tom Roar \\ Eikebrokk \\ University of \\ Agder, Norway \\ tom.eikebrokk@u \\ ia.no
}

\author{
Carl Erik Moe \\ University of \\ Agder, \\ Norway \\ carl.e.moe@ui \\ a.no
}

\author{
Rony Medaglia \\ Copenhagen \\ Business \\ School, \\ Denmark \\ rm.itm@cbs.dk
}

\author{
Hannu Larsson \\ Orebro \\ University, \\ Sweden \\ Hannu.Larsson \\ @oru.se
}

\author{
Tommi \\ Tapanainen \\ Hanyang \\ University, \\ Korea \\ tojuta@gmail.co
}

\begin{abstract}
The implementation of Health Information Technology (HIT) can improve the provision of highquality and efficient healthcare services; however, it has met with significant challenges in many cases. Despite the challenges occurring in many countries, prior research on HIT implementation success factors is, however, mainly from the USA. This research conducted a survey to IT managers in Nordic countries' healthcare organizations and compiled a list of the HIT implementation success factors that these managers considered important in each country. It was found that IT managers in Nordic countries agree highly with each other in their judgment of the importance of these success factors. While Nordic countries' healthcare systems and culture are relatively similar, the results suggest that an internationally applicable set of recommendations for the successful completion of HIT implementations could be within the realm of possibility.
\end{abstract}

\section{Introduction}

Many scholars have proposed ways to improve the success rate of Health Information Technology (HIT) implementation (e.g. [1], [2], [3], [4], [5], [6], [7]). One important facet that has been discussed is identifying the success factors (SFs) for HIT implementation. While a list of these SFs has been drawn by prior literature, not all studies have found the same SFs. For instance, Wen et al. [8] proposed a model to predict the success of an interactive health communication system (IHCS) which consists of organizational and tactical factors. Through a pilot Delphi method, Brender et al. [4] developed a list of
110 SFs for HIT implementation which comprises various success factors from twelve perspectives: (1) functional, (2) organizational, (3) behavioral, (4) cultural, (5) political, (6) management, (7) technical, (8) legal aspects, (9) strategy (10) economy, (11) education and (12) user acceptance. Rahimi et al. [9] used a qualitative meta-analysis to identify a list of 11 SFs associated with HIT implementation and analyzed the importance of these factors in different actions of implementation. Ash et al. [1] grouped related sub-factors to form 12 principles for a success of Computerized Physician Order Entry (CPOE) Implementation. Nguyen at al. [10] reviewed the existing literature and identified 16 SFs for HIT. They also suggested a taxonomy which shows the interactions of different stakeholders with implementers.

Different studies have reported different subsets of SFs rather than a comprehensive set of similar factors which are the key to success in HIT implementation. One plausible reason for this inconsistency in findings is the fact that different implementation projects have emphasized different elements for success. Other factors that could have had an effect on the result are differences in contexts with government regulations, economic environments, and organizational and national cultures.

In summary, the differences among the set of SFs for HIT implementation may be evident in two distinct levels of analysis, the organization and the country. According to Nguyen et al. [10], the study on SFs of HIT implementation is of global interest. The majority of previous studies were conducted in North America (69.45\%), of those $61.11 \%$ and $8.34 \%$ were from the United States and Canada respectively. $19.45 \%$ of papers were from European countries (the Netherlands: 2, the United Kingdom: 2, Italy: 1, 
Sweden: 1, and Spain: 1). The remainder was from Australia (1), Israel (1), and Mexico (1) [10]. Given that the current set of all HIT implementation SFs are mostly derived from North America, how would their relative importance be judged by European IT managers in the healthcare sector? Would these European IT managers evaluate their relevance equally, regardless of the country they come from? So far, little work has been done to systematically categorize the SFs for HIT implementation in this way, and to collect empirical evidence on their relative importance. To our knowledge, there are no prior studies on the country-level comparisons of these SFs. This would be the first step to isolate the hypothetical common set of SFs for any HIT implementation. Therefore, the aims of this study are: (1) to identify the success factor priorities through an empirical investigation; and (2) to compare the success factor priorities profile across countries.

The structure of this paper is as follows. Section 2 describes the research method. Section 3 focuses on answering the question of who are IT managers of healthcare organizations. The SF priorities and the comparison results are reported and discussed in Section 4 and 5. The final section suggests the implications and future research.

\section{Research Method}

\subsection{Instrument Development}

The guidelines of Straub and Carlson [59], and Straub et al. [60] about the content validity were used to design the research. First, a literature review [10], which extracted 15 success factors for HIT implementation, was used to create the questionnaire. Then, the questionnaire was pilot tested with four experts in information management, one IT project manager and one CIO. After considering their comments and suggestions the questionnaire was revised into a total of 25 success factors as shown in Appendix 1 [11]. The questionnaire was translated into Danish, Finnish, Norwegian and Swedish and a link to the questionnaire was sent to the respondents. The basic data portion asked the background information of IT managers such as the type of their organization, their experience and education and the position of their IT department. In the success factor part, the IT managers were asked to evaluate and show their degree of perceived importance for each factor in a 7-point Likert-type scale where the lower score corresponds to a more important factor. In the questionnaire, both the terms "Chief Information Officer (CIO)" and IT managers were used because usage of the title varies considerably across organizations ([12], [13]).

\subsection{Survey Administration}

As no comprehensive source of information was available on IT managers in the healthcare organizations of these Nordic countries, the list of research subjects was created manually. We used two methods to find the respondents. The first focus group comprises people who were found directly by the researchers. Because not all potential respondents could be found directly, the second focus group was composed of people who were contact persons in the target organizations. In this case, the contact persons were asked to forward the questionnaire to "the individual who is responsible for the automated information systems in your hospital". After adjustment for non-working email addresses and additional references from the contact persons, the final list of potential respondents who received the instrument included 309 persons (Denmark 85, Finland 109, Norway 69 and Sweden 46). The survey duration was two months and a total of 94 responses was received which equals to a $30.42 \%$ response rate.

Since the questionnaire was sent via two different channels, it is necessary to ensure that the respondents were, in fact, in the correct target group, that is IT managers who have clear responsibilities for HIT implementation in their organizations. The criteria for screening respondents were based on background data from the respondents such as their titles and their known departmental functions (see [14] for similar criteria). The screening was made by two of the researchers working together. After screening, all respondents from Norway and Denmark were included. In Finland, of the 34 responses, two were screened out since one was an expert doctor in a temporary position and the other was a security chief and thus excluded from the IT management function of the organization. In Sweden of the 21 responses, one was screened out since he/she was a human resources manager and had not implemented any HIT projects. Thus, a total of 91 responses (i.e. 14 from Denmark, 32 from Finland, 25 from Norway and 20 from Sweden) were included in the study reported here. The portion of the data gathered from Finland has previously been used in a separate article (see [11]).

Table 1: Profile of respondents by countries

\begin{tabular}{|l|c|c|}
\hline Countries & Number of respondents & $\%$ \\
\hline Denmark & 14 & 15.38 \\
\hline
\end{tabular}




\begin{tabular}{|l|c|c|}
\hline Finland & 32 & 35.16 \\
\hline Norway & 25 & 27.47 \\
\hline Sweden & 20 & 21.98 \\
\hline Total & 91 & 100.00 \\
\hline
\end{tabular}

\section{Who are IT Managers?}

The average age of the respondents is 50.42 years old and thus they had extensive experience in the field. Almost $60 \%$ of respondents had a previous job in management positions prior to becoming IT managers (see Table 2 below).

Table 2: Previous management experience

\begin{tabular}{|c|c|c|c|}
\hline Countries & $\begin{array}{c}\text { Previous Management } \\
\text { Positions }\end{array}$ & Total & $\%$ \\
\hline Denmark & 8 & 14 & 57.14 \\
\hline Finland & 16 & 32 & 50.00 \\
\hline Norway & 19 & 25 & 76.00 \\
\hline Sweden & 11 & 20 & 55.00 \\
\hline Total & 54 & 91 & 59.34 \\
\hline
\end{tabular}

The proportion of female IT managers overall is around $36 \%$. There is an even number of female and male IT managers in Finland and Sweden. However, $92 \%$ of Norwegian IT managers who participated in this survey are male.

The most popular education background of respondents is technical (over 40\% in three countries: Denmark, Finland and Norway). IT managers with nursing background are common in Finland (i.e. $18.75 \%$ ), while they are relatively few in Denmark, Norway and Sweden (i.e. 7.14\%, 4.17\% and 5.00\% respectively). Except for Denmark (14.29\%) and Sweden (5.00), there were no IT managers with a clinical background in Finland and Norway.

Table 3: The recruitment method

\begin{tabular}{|l|c|c|}
\hline Countries & External (\%) & Internal (\%) \\
\hline Denmark & 63.64 & 36.36 \\
\hline Finland & 46.88 & 53.13 \\
\hline
\end{tabular}

\begin{tabular}{|c|c|c|}
\hline Norway & 33.33 & 66.67 \\
\hline Sweden & 55.00 & 45.00 \\
\hline Total & 49.41 & 50.59 \\
\hline
\end{tabular}

Both the internal (i.e. promotion or transfer) and external recruitment methods are used to appoint IT managers in healthcare organizations in Nordic countries. The data from the survey shows that IT managers are recruited equally often from internal and external sources at average of around $50 \%$. Norway has the highest number of IT managers recruited from internal sources $(67 \%)$ while Denmark has the highest number of externally recruited managers (64\%) as shown in Table 3 above.

The ICT sector has relatively large shares of the young employees who are below 35 years old [15]. Since respondents in this survey are IT managers it is reflected in a quite high average age (around 51 years old). In general, the Nordic countries have relatively large shares of women on the labor market and based on the report of "The ICT Sector in Nordic countries 1995-2000" [15], the share of females employed in the ICT services was around $30 \%$ and more or less identical among the Nordic countries. For this survey, $36 \%$ of respondents were female IT managers. Regarding education background of CIOs/IT managers, Gottschalk [12] reported that the majority (58\%) of Norwegian CIOs responding to a survey had completed either a Master's or Bachelor's degree. Earlier research by Stephens et al. [14] noted that $60 \%$ and $59 \%$, respectively, of responding U.S. CIOs having a "business-related" degree. IT managers in healthcare organizations in the Nordic countries also have high education level reflecting the knowledge-intensive character of this sector. The major background is technical (38.53\%), followed by business school (14.35\%) and medical science $(13.59 \%)$.

\section{Results}

\subsection{Success Factor Priorities}

The average rating of SFs for all four countries are counted and used to rank SFs. The ten most important SFs are: (1) commitment and support of leaders, (2) system quality, (3) end-user participant, (4) information and service quality, (5) infrastructure, (6) department cooperation, (7) resources, (8) staff training, (9) co-development of the system and workflow, and (10) vendor cooperation. These top 
ten SFs from the four Nordic countries are the same as identified in the prior study using only Finnish data [11] only the relative positions of some of SFs within the top ten are slightly different. Furthermore, these top ten SFs are also almost identical for the three other Nordic countries.

\subsection{Cross-country Comparison}

To investigate differences in the perception of IT managers from different countries, the ranking of the success factors in the four countries were compared. Even though the country proportion is different (i.e. Denmark: 15.38\%; Finland: 35.16\%; Norway: 27.47\%; Sweden: $21.98 \%$ in Table 1), four diagrams have almost a similar pattern as is shown in Chart 1. Thus, it is likely that despite being in different countries and contexts, IT managers have similar evaluation to certain success factors of HIT implementation.

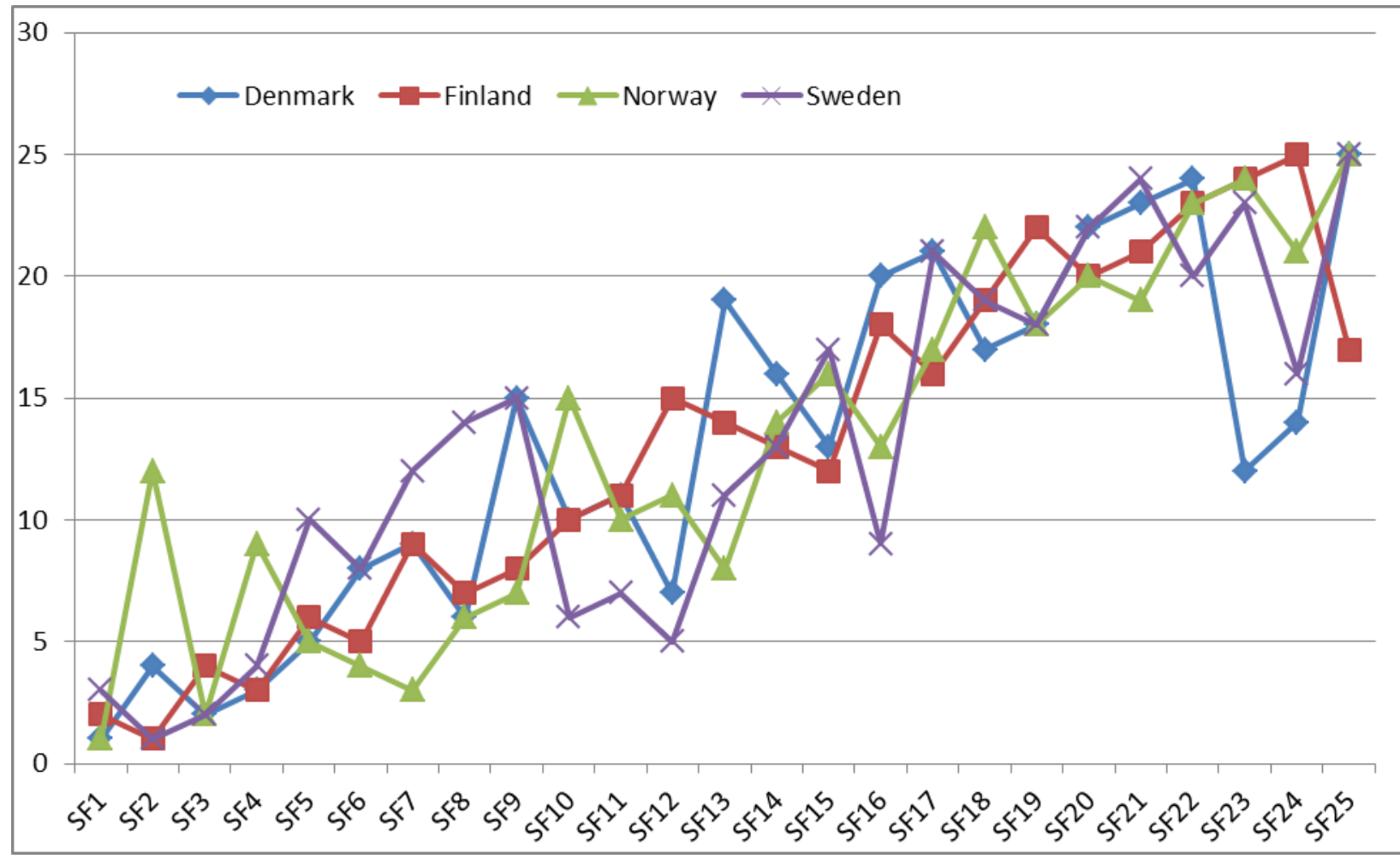

Chart 1: Success factor priorities comparison

Despite similarities, as can be seen from Chart 1, some differences exist. For example, "system quality (SF2), organization openness (SF16), regulation (SF23), incentives (SF24) and influence of external environment (SF25)" vary between these countries. Particularly, the Danish IT managers might consider the role of incentives and regulation in promoting HIT more important than other countries particularly in comparison with the view of Finnish IT managers. On the other hand, Finnish IT managers emphasized the influence of external environment at $17^{\text {th }}$ position while the rest valued it at the $25^{\text {th }}$ position. Swedish IT managers might be quite different from the others regarding the role of organization openness to change and innovation (SF16). Finally, in Norway, the system quality is not in the top ten $\left(12^{\text {th }}\right.$ position $)$ while IT managers of three other countries viewed this factor as extremely important (ranked 1 in Finland, ( 2 in Sweden and 3 in Denmark).

\subsection{Success Factors and Organization Types}

The survey sample was divided into two groups: the large hospitals (e.g. university and regional hospitals) which accounts for around $41.76 \%$ of the sample and the small organizations which includes all other types of healthcare organizations. The success factor priorities between the big and small healthcare organizations were compared. It is found that the 
ranking list of the group of big healthcare organizations is almost the same as the group of the small healthcare organizations. However, the perception differences in the staff training (SF8) and the co-development of the system and workflow (SF9) are relatively large (6 and 5 positions difference respectively).

\section{Discussion}

The questionnaire used in this study was based on the literature review where most studies came from North America. However, the similarity in HIT implementation success factor priorities in the empirical data from the Nordic countries suggests that these success factor priorities profiles can be applicable in several countries. In addition, previous literature reviews of Enterprise Resource Planning (ERP) related SFs (e.g. [16], [17]) also found that there is a set of factors such as top management support, excellent project management that are fundamental to successful implementation of ERP and common to most ERP adopting organizations. This study accommodates their argument but in the context of HIT implementation. This could imply that some success factors in IS implementation share the same characteristics. While country-level similarities were identified in the IT manager -reported HIT implementation success factors in this research, we also noted that there were certain differences between the countries that could be due to a number of reasons, for example organizational and government policies.

Regarding success factors and organization types, the research of Saini et al. [18] found insignificant differences in success factors of ERP at Indian SMEs compared with Indian large organizations. Our research is conducted in the area of HIT implementation but shows similar results. The size of organizations seems unimportant in relation to their IT managers' evaluations of SFs except for the codevelopment of the system and workflow, and staff raining. For these factors, IT managers in small healthcare organizations might perceive the "codevelopment of the system and workflow or business process re-engineering as less important than their colleagues in the big organizations. Instead, they might emphasize more the role of staff training. One of the reasons could be in the small clinics the business re-engineering process might not be as difficult as in big clinics, while they might need to increase more IT knowledge for their staff.

\section{Implications and Conclusions}

Several prior studies have focused on the success factors of HIT implementations. Literature reviews have identified a set of HIT implementation success factors that are derived from many stakeholder groups in various countries. There have thus far, however, been few attempts to empirically examine the importance of these success factors across contexts. To our knowledge, this is the first study that collected this empirical data from several countries and also contrasted the view of IT managers across these countries. As the profile of HIT implementation success factor priorities from the four surveyed countries are relatively similar, this study suggests that a common set of critical success factors for HIT implementation may be derived and used in a range of countries. If this would be the case, recommendations for HIT implementations throughout the world can be made on a much more solid footing. If certain similarities are consistent across the countries, it may be possible to derive the list of fundamental success factors with little variances across countries. This would lead to establish a set of some management standards which IT managers can base on to promote the international cooperation and celebration. It would also diminish the contextually oriented view regarding the differences in national culture, management style, organizational forms, and policy structures.

For example, this research suggests that lessons learned by top IT experts in HIT implementation can be applicable internationally, and that seminars, workshops, and conferences that introduce foreign cases can contribute with interesting findings derived locally. Human resources transfer between countries regarding HIT development and implementation can also bring more benefits to organizations than thought thus far. In particular, the projects that would benefit most would be those that take place in countries with relatively low capabilities for HIT implementation or few local experiences. Future research should attempt to confirm whether the list of priorities for HIT implementation success factors is applicable also for other parts of the world.

This study also indicates that Nordic IT managers may have certain differences in perceptions. While organizational types seem not appear to play a role, these differences may result from subtle variations in the healthcare system or organizational features, for instance, and therefore, future research is needed to account for these contextual issues. There is also a possibility that these differences are due to methodological issues. Another possibility is that a situation exists whereby certain SFs are consistently 
similar among the countries whereas others vary. This could be object for further study.

One limitation of this research relates to the difficulty of identifying the relevant respondents since there is no clear official information source which provides information about IT managers and the complex IT healthcare structure in the Nordic countries. In addition, this study reflects the views of surveyed IT managers which may be different from those of other stakeholders such as end-users. If the results of this study can be compared to a similar survey of the other stakeholders, it would be more informative. Finally, as the Nordic countries have rather similarities in culture and healthcare systems, further verification for the results of this study would be desirable.

\section{References}

[1] Ash, J. S., Stavri, P. Z., \& Kuperman, Gilad J., “A Consensus Statement on Considerations for a Successful CPOE Implementation", Journal of American Medical Informatics Association, Vol.10, N.3, 2003, pp. 229-34.

[2] Ash, J.S., Fournier, L., Stavri, P.Z., \& Dykstra, R.., "Principles for a successful computerized physician order entry implementation", in AMIA Annual Symposium Proceedings, 2003, pp. 36-40

[3] Ash, J. S., Chin, H. L., Sittig, D. F., \& Dykstra, R. H., "Ambulatory computerized physician order entry implementation", in AMIA Annual Symposium Proceedings, 2005, pp. 11-15.

[4] Brender, J., Ammenwerth, E., Nykanen, P., Talmon, J., "Factors influencing success and failure of health informatics systems: A Pilot Delphi Study", Methods of Information in Medicine, 45, 2006, pp. 125-136.

[5] Heeks, Richard, "Health information systems: Failure, success and improvisation", International Journal of Medical Informatics, 75, 2006, pp. 125-137.

[6] Kaplan, Bonnie and Harris-Salamone, Kimberly D., "Health IT success and failure: recommendations from literature and an AMIA workshop", Journal of the American Medical Informatics Association, 16 (3), 2009, pp. 291-299.

[7] Martikainena, Susanna, Viitanenb, Johanna, Korpelaa, Mikko, Lääveri, Tinja, 'Physicians' experiences of participation in healthcare IT development in Finland: Willing but not able", International journal of medical informatics, 81, 2012, pp. 98-113.

[8] Wen, Kuang-Yi, Gustafson, David H., Hawkins, Robert P., Brennan, Patricia F., Dinauer, Susan, Johnson, Pauley R., Siegler, Tracy, Developing and validating a model to predict the success of an IHCS implementation: the readiness for implementation model, Journal of the American Medical Informatics Association, 2010; 17: 70713.

[9] Rahimi, Bahlol, Vimarlund, Vivian, Timpka, Toomas, Health Information System Implementation: A Qualitative Meta-analysis, Journal of Medicine System, Vol. 33, 2009, p. $359-68$.

[10] Nguyen, Hai Thi Thanh, Saranto, Kaija, Tapanainen, Tommi \& Ishmatova, Diana, "A Review of Health Information Technology Implementation Success Factors: Importance of the regulatory and financing environment", Hawaii International Conference on System Science (HICSS)-47, Hawaii, USA, 2014.

[11] Nguyen, Hai Thi Thanh, Tapanainen, Tommi. and Ishmatova, Diana., "Critical Success Factors in Health Information Technology Implementation: The perspective of Finnish Information Technology (IT) executives", International Journal of Healthcare Information Systems and Informatics, in press.

[12] Gottschalk, Petter, "Strategic management of IS/IT functions: the role of the CIO in Norwegian organizations", International Journal of Information Management, 19, 1999, pp. 389-399

[13] Lepore, Dawn, “Are CIOs Obsolete?", Harvard Business Review, 2000

[14] Stephens, Charlotte S., Ledbetter, William N., Mitra, Amitava, Ford, Neison F., "Executive or Functional Manager? The Nature of the CIO's job", MIS Quarterly, 16 (4), 1992, pp. 449-467

[15] Statistics Denmark, Statistics Finland, Statistics Iceland, Statistics Norway, Statistics Sweden, The ICT Sector in Nordic countries 1995-2000, Denmark, 2001, last accessed 10 May 2014 at www.dst.dk/ict

[16] Moohebat, Mohammad Reza, Asemi, Asefeh, Jazi, Mohammad Davarpanah, "A Comparative Study of Critical Success Factors (CSFs) in Implementation of ERP in Developed and Developing Countries", International Journal of Advancements in Computing Technology, Vol. 2 (5), 2010.

[17] Ngai, E. W. T, Law, C. C. H, Wat, F. K. T, "Examining the critical success factors in the adoption of enterprise resource planning", Computers in Industry, Vol. 59, 2008, pp. 548-564.

[18] Saini, Shashank, Nigam, Siddhartha, Misra, Subhas, C., "Identifying success factors for implementation of ERP at Indian SMEs: A comparative study with Indian large organizations and the global trend", Journal of Modeling in Management, Vol. 8, No. 1, 2013, pp. 103-122.

[19] Amirfar, S., Taverna J., Anane, S., \& Singer, J., "Developing public health clinical decision support systems 
(CDSS) for the outpatient community in New York City: our experience", BMC Public Health. 30; 11, 2011, 753.

[20] Gagnon, Marie-Pierre, Desmartis, Marie \& Labrecque, Michel, "Implementation of an electronic medical record in family practice: a case study, "Informatics in Primary Care, 18, 2010), pp. 31-40.

[21] Devine, E. B., Wilson-Norton, J. L., Lawless, N. M., Hansen, R. N., Hollingworth, W., Fisk, A. W., \& Sullivan, S. D., "Implementing an Ambulatory e-Prescribing System: Strategies Employed and Lessons Learned to Minimize Unintended Consequences". In Henriksen, K., Battles, J. B., Keyes, M. A., Grady, M. L., editors. Advances in Patient Safety: New Directions and Alternative Approaches (Vol. 4: Technology and Medication Safety). Rockville (MD): Agency for Healthcare Research and Quality (US), 2008.

[22] Klehr, Joan, Hafner, Jennifer, Spelz, Leah Mylrea, Steen, Sara \& Weaver, Kathy, "Implementation of Standardized Nomenclature in the Electronic Medical Record, International Journal of Nursing Terminologies and Classifications Vol.20, No.4, 2009, pp. 169-180.

[23] Alexander, Susan, Frith, Karen H., O'Keefe, Louise \& Hennigan, Michael A., "Implementation of Customized Health Information Technology in Diabetes SelfManagement Programs", Clinical Nurse Specialist, 25(2), 2011, pp. 63-70

[24] Box, T. L., McDonell, M., Helfrich, C. D., Jesse, R. L., Fihn, S. D., \& Rumsfeld, J. S., "Strategies from a nationwide health information technology implementation: the VA CART story", .Journal of General Internal Medicine. 25 Suppl 1, 2010, p. 72-76

[25] Lowery, Mandy, Dobbs, J. \& Monkhouse A., "Embedding an electronic health record within a health visiting service", Community Practitioner, 85(9), 2012, pp. 20-23.

[26] Ludwick, D. A., Doucette, J., "Adopting electronic medical records in primary care: lessons learned from health information systems implementation experience in seven countries", International Journal of Medical Informatics. 78(1), 2009, pp. 22-31.

[27] Postemaa, T. R. F., Peetersb, J. M., \& Friele, R. D., "Key factors influencing the implementation success of a home telecare application", International Journal of Medical Informatics, Vol. 81, 2012, pp. 415-423.

[28] Sharkey, Siobhan, Hudak, Sandra, Horn, Susan D., Barrett, Ryan, Spector, William \& Limcangco, Rhona, "Exploratory Study of Nursing Home Factors Associated with Successful Implementation of Clinical Decision Support Tools for Pressure Ulcer Prevention", Advances in skin \& wound care, 26(2), 2013, pp. 83-92
[29] Silvester, B. V. \& Carr, S. J., "A shared electronic health record: lessons from the coalface", Medicine Journal of Australia, 190 (11 Suppl), 2009, pp. 113-116.

[30] Upton, Mark, "The Royal Hobart Hospital digital medical records success story", Health Information Management Journal, Vol.37 No.1, 2008, pp. 46-54

[31] Wolf, Debra M., Greenhouse, Pamela K., Diamond, Joel N., Ferd, William \& McCormick, Donna, "Community Hospital Successfully Implements e-Record and CPOE", CIN: Computers, Informatics, Nursing, 24(6), 2006, pp. 307-316.

[32] Baron, R. J., Fabens, E. L., Schiffman, M., \& Wolf, E., "Electronic health records: just around the corner? Or over the cliff?", Annals of Internal Medicine, 143(3), 2005, pp. 222-226.

[33] Fullerton, C., Aponte, P., Hopkins, R., Bragg, D., \& Ballard, D. J., "Lessons learned from pilot site implementation of an ambulatory electronic health record", In Proceedings of Baylor University Medical Center, 19(4), 2006, pp. 303-310.

[34] Jacobs, Brian R., Hallstro, Craig K., Hart, Kim Ward, Mahoney, Daniela \& Lykowski, Gayle, "The Clinical Informatics Outcomes Research Group, Lessons from a Successful Implementation of a Computerized Provider Order Entry System”, Journal of Pediatric Pharmacology and Therapeutics, , Vol. 12 No. 2, 2007

[35] Jeskey, M., Card, E., Nelson, D., Mercaldo, N. D., Sanders, N., \& Higgins, M. S., "Nurse adoption of continuous patient monitoring on acute post-surgical units: Managing technology implementation", Journal of Nursing Management, 19(7), 2011, pp. 863-875.

[36] Lorenzi, N. M., Novak, L. L., Weiss, J. B., Gadd, C. S., \& Unertl, K. M., "Crossing the implementation chasm: a proposal for bold action", Journal of the American Medical Informatics Association, 15(3), 2008, 290-296.

[37] Urda, D., Ribelles, N., Subirats, J. L., Franco, L., Alba, E., \& Jerez, J. M., "Addressing critical issues in the development of an Oncology Information System", International Journal of Medical Informatics, Vol. 82, (5), 2013, pp. 398-407.

[38] Bar-Lev, S., \& Harrison, M. I., "Negotiating time scripts during implementation of an electronic medical record", Health Care Management Review, 31(1), 2006, pp. $\underline{11-17 .}$

[39] Dennehy, P., White, M. P, Hamilton, A., Pohl, J. M, Tanner, C., Onifade, T. J., \& Zheng, K., "A partnership model for implementing electronic health records in resource-limited primary care settings: experiences from two nurse-managed health centers", Journal of the American Medical Informatics Association, 18(6), 2011, pp. 820-826. 
[40] Hernández-Ávila, Juan Eugenio, Palacio-Mejía, Lina Sofia, Lara-Esqueda, Agustín, Silvestre, Eva, AgudeloBotero, Marcela, Diana, Mark L., Hotchkiss, David R., Plaza, Beatriz, Parbul, \& Alicia Sanchez, "Assessing the process of designing and implementing electronic health records in a statewide public health system: the case of Colima, Mexico", Journal of the American Medical Informatics Association, 20, 2013, pp. 238-244.

[41] Mazzoleni, M. C., "Why a system awarded as "MIE '99 Best Paper" failed to be used and hence to affect patient's health?" Methods of Information in Medicine, 45(1), 2006, pp. 90-94.

[42] Boddy, David, King, Gerry, Clark, Julia S., Heaney, David \& Mair, Frances, "The influence of context and process when implementing e-Health", BMC Medical Informatics and Decision Making, 9:9, 2009

[43] Vreeman, D. J., Taggard, S. L., Rhine, M. D., \& Worrell, T. W., "Evidence for electronic health record systems in physical therapy", Physical Therapy, 86(3):434-46; discussion, 2006, pp. 446-449.

[44] Batley, N. J., Osman, H. O., Kazzi, A. A., \& Musallam, K. M., "Implementation of an emergency department computer system: design features that users value", The Journal of Emergency Medicine. 41(6), 2011, pp. 693-700.

[45] Nykänen, P. \& Karimaa, E., "Success and failure factors in the regional health information system design process--results from a constructive evaluation study", Methods of Information in Medicine, 45(1), 2006, pp. 85-89.

[46] Gustafson, David H., Brennan, Patricia Flatley \& Robert P. Hawkins, "Investing in E-Health: What it Takes to Sustain Consumer Health Informatics", 2007, Springer

[47] Fisher, Jill A. \& Monahan, Torin, Tracking the social dimensions of RFID systems in hospitals, International Journal of Medical Informatics, 77, 2008, pp. 176-183.

[48] Cripps, H. \& Standing, C., "The implementation of electronic health records: a case study of bush computing the Ngaanyatjarra lands", International Journal of Medical Informatics, 80(12), 2011, pp. 841-848

[49] McGinn, C. A., Grenier, S., Duplantie, J., Shaw, N., Sicotte, C., Mathieu, L., Leduc, Y., Légaré, F., \& Gagnon, M. P., "Comparison of user groups' perspectives of barriers and facilitators to implementing electronic health records: a systematic review", BMC Medicine, 2011, pp. 9-46.

[50] Kijsanayotin, Boonchai, Pannarunothai, Supasit, Speedie \& Stuart M., "Factors influencing health information technology adoption in Thailand's community health centers: Applying the UTAUT model", International Journal of Medical Informatics, 78, 2009, pp. 404-416.
[51] Nesbitt, Thomas S., Cole, Stacey L., Pellegrino, Lorraine \& Keast, Patricia, "Rural Outreach in Home Telehealth: Assessing Challenges and Reviewing Successes", Telemedicine and e-Health, Vol. 12, No. 2, 2006.

[52] Archer, N., \& Cocosila, M., "A comparison of physician pre-adoption and adoption views on electronic health records in Canadian medical practices", Journal of Medical Internet Research, 13(3):e57, 2011.

[53] Gagnon, M. P., Duplantie, J., Fortin, J. P., Lamothe, L., Légaré, F., Labrecque, M., "Integrating scientific evidence to support telehomecare development in a remote region", Telemedicine and E-Health, 15(2), 2009, pp. 195198.

[54] Maust, D. D., "Implementation of an electronic medical record in a health system: lessons learned", Journal for nurses in staff development: JNSD: official journal of the National Nursing Staff Development Organization, Vol. 28, No. 1, 2012, pp. E11-E15.

[55] Callen, Joanne L., Braithwaite, Jeffrey \& Westbrook, Johanna I., "Contextual Implementation Model: a framework for assisting clinical information system implementations", Journal of the American Medical Informatics Association, 15 (2), 2008, pp. 255-261

[56] Lau, Francis, Price, Morgan, Boyd, Jeanette, Partridge, Colin, Bell, Heidi \& Raworth, Rebecca., "Impact of electronic medical record on physician practice in office settings: a systematic review", BMC Medical Informatics and Decision Making, 12:10, 2012

[57] Lorenzi, N. M. \& Riley, R. T., "Managing change: an overview", Journal of the American Medical Informatics Association, 7(2), 2000, pp. 116-24.

[58] Vitacca, M., Mazzu, M. \& Scalvini, S., "Sociotechnical and organizational challenges to wider e-Health implementation", Chronic Respiratory Disease, 6, 2009, pp. 91-97

[59] Straub, Detmar, W. and Carlson, Curtis, L., "Validating Instruments In MIS Research", MIS Quarterly, 13, 2, 1989, pp.147-169

[60] Straub, Detmar, W., Boudreau, Marie-Claude, and Gefen, David, "Validation Guidelines for IS Positivist Research", Communications of the AIS, 13, 2004, pp.380-427 
Appendix 1: Summary of literature review on success factors of HIT implementation

\begin{tabular}{|c|c|c|c|}
\hline ID & Success Factors & Description & References \\
\hline SF1 & $\begin{array}{l}\text { Commitment } \\
\text { support of leaders }\end{array}$ & $\begin{array}{l}\text { Providing support for the project team to } \\
\text { overcome the obstacles to implement the systems } \\
\text { successfully }\end{array}$ & {$[19] ;[20] ;[21] ;[22]$} \\
\hline $\mathrm{SF} 2$ & System quality & $\begin{array}{l}\text { Level of quality characteristics set for the } \\
\text { technical system, such as reliability, response time } \\
\text { and flexibility of the system }\end{array}$ & 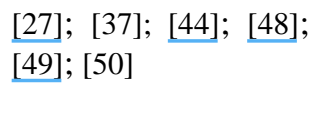 \\
\hline SF3 & $\begin{array}{l}\text { End-user participation } \\
\text { and involvement }\end{array}$ & $\begin{array}{l}\text { Involving the end-users in various stages of the } \\
\text { project, including requirements definition, } \\
\text { planning, development, and testing }\end{array}$ & $\begin{array}{l}\text { [21]; [23]; [28]; [29]; } \\
\text { [31]; [35]; [37]; [38]; } \\
{[42] ;[43] ;[44] ;[45]}\end{array}$ \\
\hline SF4 & $\begin{array}{l}\text { Service and information } \\
\text { quality }\end{array}$ & $\begin{array}{l}\text { Level of quality characteristics set for the service } \\
\text { and information quality, such as accuracy, } \\
\text { timeliness and responsiveness }\end{array}$ & $\begin{array}{l}\text { [27]; [37]; [44]; } \underline{[48]} ; \\
{[49] ;[50]}\end{array}$ \\
\hline SF5 & Infrastructure Quality & $\begin{array}{l}\text { Telecommunications capability, rigorous security, } \\
\text { interoperability, standardization, and connectivity } \\
\text { of clinical information systems }\end{array}$ & $\underline{[21]} ; \underline{[29]} ; \underline{[30]} ;[32] ;$ \\
\hline SF6 & $\begin{array}{l}\text { Cooperation among } \\
\text { administration, IT, and } \\
\text { clinical functions }\end{array}$ & $\begin{array}{l}\text { A collaborative relationship between physicians, } \\
\text { researchers, hospital administrators, IT specialists, } \\
\text { end-users, and external stakeholders }\end{array}$ & $\begin{array}{l}{[22] ;[38] ;[39] ; \underline{[40] ;}} \\
\underline{[41]}\end{array}$ \\
\hline SF7 & Sufficient resources & $\begin{array}{l}\text { Resources from the healthcare organization or } \\
\text { other sources which ensure the sustainability of } \\
\text { the implementation project }\end{array}$ & [22]; [32]; [40]; [51] \\
\hline SF8 & Staff training & $\begin{array}{l}\text { Training provided to the end-users which is } \\
\text { sufficient in quantity and quality to increase end- } \\
\text { user acceptance of the system }\end{array}$ & $\begin{array}{l}{[1] ;[21] ;[23] ;[28] ;} \\
{[32] ;[33] ;[34] ;[43] ;} \\
{[52] ;[51] ;[53] ;[54]}\end{array}$ \\
\hline SF9 & $\begin{array}{l}\text { Co-development of the } \\
\text { system and the workflow }\end{array}$ & $\begin{array}{l}\text { Concurrent design and development of the } \\
\text { technical system and the work process it is to } \\
\text { support }\end{array}$ & $\begin{array}{l}\text { [21]; [28]; [30]; [32]; } \\
{[35] ;[37] ;[38] ;[42] ;} \\
\text { [43] }\end{array}$ \\
\hline SF10 & $\begin{array}{l}\text { Collaboration with the } \\
\text { vendors }\end{array}$ & $\begin{array}{l}\text { A collaborative relationship between the } \\
\text { healthcare organizations and IT vendors which } \\
\text { helps to inform the organization of new IT and its } \\
\text { potential }\end{array}$ & [19]; [32]; [35] \\
\hline SF11 & Project management & $\begin{array}{l}\text { Activities define the scope, schedule and budget of } \\
\text { the project and include methods to identify, } \\
\text { evaluate and avoid problems }\end{array}$ & 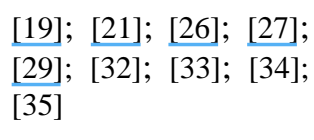 \\
\hline SF13 & $\begin{array}{l}\text { Multi-disciplinary } \\
\text { teamwork }\end{array}$ & $\begin{array}{l}\text { The project group includes representatives from } \\
\text { different units such as the IT, administration and } \\
\text { clinical departments }\end{array}$ & $\underline{\underline{[21] ;}[31] ;[33] ;[34] ;}$ \\
\hline SF14 & Performance of project & The degree to which the project team is able to & [21]; [31]; [33]; [36]; \\
\hline
\end{tabular}




\begin{tabular}{|c|c|c|c|}
\hline & team & $\begin{array}{l}\text { obtain the objectives set to the project, such as } \\
\text { keep within the budget and schedule }\end{array}$ & [37] \\
\hline SF12 & $\begin{array}{l}\text { Meeting the need of end- } \\
\text { users }\end{array}$ & $\begin{array}{l}\text { Understanding the needs of users in several levels, } \\
\text { and then meeting these needs }\end{array}$ & [30]; [42]; [46]; [47] \\
\hline SF15 & Technical Support & $\begin{array}{l}\text { Support provided to the end-users in trouble- } \\
\text { shooting situations which helps them to overcome } \\
\text { the problem and foster organizational learning } \\
\text { regarding the technology }\end{array}$ & $\begin{array}{l}{[1] ; \underline{[21] ;[23] ;[28] ;}} \\
{[32] ;[33] ;[34] ; \underline{433]}} \\
{[51] ;[52] ;[53] ;[54]}\end{array}$ \\
\hline SF16 & $\begin{array}{l}\text { Organization openness } \\
\text { change and innovation }\end{array}$ & $\begin{array}{l}\text { Organizational culture that encourages use of } \\
\text { systems, and the presence of individuals and } \\
\text { opinion leaders who are keen to adopt systems }\end{array}$ & {$[20] ; \underline{[26]} ;[28] ;[46] ;$} \\
\hline SF17 & $\begin{array}{l}\text { Meeting the need of } \\
\text { management }\end{array}$ & $\begin{array}{l}\text { Understanding key organizational objectives and } \\
\text { management needs, and then meeting these } \\
\text { objectives and needs }\end{array}$ & [8]; [31]; [46] \\
\hline SF18 & Organization Strategy & $\begin{array}{l}\text { Planned activities which aim at achieving certain } \\
\text { organizational goals }\end{array}$ & [36]; [55]; [56]; [57] \\
\hline SF19 & $\begin{array}{l}\text { Experience in change } \\
\text { and innovation }\end{array}$ & $\begin{array}{l}\text { A history of organizational changes and in using } \\
\text { health information systems that can spur the } \\
\text { adoption of new systems }\end{array}$ & 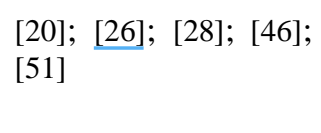 \\
\hline $\mathrm{SF} 20$ & $\begin{array}{l}\text { Information } \\
\text { Communication } \\
\text { Technology } \\
\text { Strategy }\end{array}$ & $\begin{array}{l}\text { Defining how ICT can be used within an } \\
\text { organization as part of achieving goals and } \\
\text { objectives of the organization }\end{array}$ & {$[8] ;[42]$} \\
\hline $\mathrm{SF} 21$ & $\begin{array}{l}\text { Meeting the need of } \\
\text { external stakeholders }\end{array}$ & $\begin{array}{l}\text { Understanding and meeting the needs specified by } \\
\text { governments and other third parties, e.g. in the } \\
\text { dimensions of patient safety, quality improvement, } \\
\text { and patient rights }\end{array}$ & {$[42] ;[46] ;[58]$} \\
\hline SF22 & Project champions & $\begin{array}{l}\text { Persons, typically executive managers, who help } \\
\text { to coordinate implementation and encourage } \\
\text { overall acceptance of the new applications by their } \\
\text { peers }\end{array}$ & 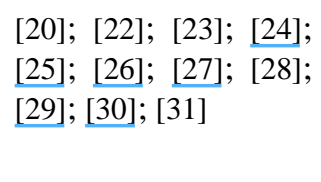 \\
\hline SF23 & Regulation & $\begin{array}{l}\text { Administrative policies which mandate the use of } \\
\text { systems, and may include punishment for non-use }\end{array}$ & $\begin{array}{l}{[1] ;} \\
{[49]}\end{array} \underline{[24]} ;[32] ; \underline{[48]} ;$ \\
\hline SF24 & Incentives & $\begin{array}{l}\text { Encouragement policies that reward the use of the } \\
\text { system, such as financial rewards }\end{array}$ & {$[1] ; \underline{[24]} ;[32] ; \underline{[48]}$} \\
\hline SF25 & $\begin{array}{l}\text { Influence of external } \\
\text { environment }\end{array}$ & $\begin{array}{l}\text { Regulatory, legislative, and economic context } \\
\text { which can influence the development of systems }\end{array}$ & 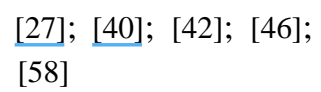 \\
\hline
\end{tabular}

